\title{
Mitoflash altered by metabolic stress in insulin-resistant skeletal muscle
}

\author{
Yi Ding ${ }^{1} \cdot$ Huaqiang Fang ${ }^{1,2} \cdot$ Wei Shang ${ }^{1,2} \cdot$ Yao Xiao $^{1} \cdot$ Tao Sun $^{1,2} \cdot$ Ning Hou $^{1}$ • \\ Lin Pan $^{1}$ - Xueting Sun ${ }^{1} \cdot$ Qi Ma $a^{1,2}$. Jingsong Zhou ${ }^{3}$ Xianhua Wang ${ }^{1,2}$. \\ Xiuqin Zhang ${ }^{1} \cdot$ Heping Cheng ${ }^{1,2}$
}

Received: 14 February 2015 /Revised: 19 March 2015 / Accepted: 23 March 2015 / Published online: 25 April 2015

(C) The Author(s) 2015. This article is published with open access at Springerlink.com

\begin{abstract}
Central to bioenergetics and reactive oxygen species (ROS) signaling, the mitochondrion plays pivotal roles in the pathogenesis of metabolic diseases. Recent advances have shown that mitochondrial flash ("mitoflash") visualized by the biosensor mt-cpYFP affords a frequency-coded, optical readout linked to mitochondrial ROS production and energy metabolism, at the resolution of a single mitochondrion. To investigate possible mitoflash responses to metabolic stress in insulin resistance (IR), we generated an mt-cpYFP-expressing $\mathrm{db} / \mathrm{db}$ mouse model with the obesity and IR phenotypes unaltered. In conjunction with in vivo imaging of skeletal muscles, we uncovered a progressive increase of mitoflash frequency along with its morphological changes. Interestingly, enhanced mitochondrial networking occurred at 12 weeks of age, and this was followed by mitochondrial fragmentation at 34 weeks. Pioglitazone treatment normalized mitoflash frequency and morphology while restored mitochondrial respiratory function and insulin sensitivity in 12 weeks mt-cpYFP $\mathrm{db} / \mathrm{db}$ mice. Mechanistic study revealed that the mitoflash remodeling was associated with altered expression of proteins involved in mitochondrial dynamics and quality control. These findings
\end{abstract}

Electronic supplementary material The online version of this article (doi:10.1007/s00109-015-1278-y) contains supplementary material, which is available to authorized users.

Xiuqin Zhang

zhangxq@pku.edu.cn

1 Institute of Molecular Medicine, Peking University, Beijing, China

2 State Key Laboratory of Membrane Biology, Peking-Tsinghua Center for Life Sciences, Beijing, China

3 Department of Molecular Biophysics and Physiology, Rush University Medical Center, Chicago, IL, USA indicate that mitoflash activity may serve as an optical functional readout of the mitochondria, a robust and sensitive biomarker to gauge IR stresses and their amelioration by therapeutic interventions.

\section{Key message}

- In vivo detection of mitochondrial flashes in mt-cpYFPexpressing $\mathrm{db} / \mathrm{db}$ mouse.

- Mitoflash frequency increased progressively with disease development.

- Mitoflash morphology revealed a biphasic change in mitochondrial networking.

- Mitoflash abnormalities and mitochondrial defects are restored by pioglitazone.

- Mitoflash may serve as a unique biomarker to gauge metabolic stress in insulin resistance.

Keywords Mitoflash · Mitochondrial dysfunction .

Metabolic stress $\cdot$ Mitochondrial biomarker

\section{Introduction}

Insulin resistance (IR), a hallmark in the pathogenesis of metabolic syndrome and type 2 diabetes [1], is characterized by deterioration in glucose tolerance resulting mainly from impaired insulin-stimulated glucose metabolism in the skeletal muscle $[2,3]$. Although the underlying mechanisms remain poorly understood, a strong relationship between increased intramuscular lipid content and muscle IR has been suggested $[4,5]$. Diminished mitochondrial oxidative activity is thought to be responsible for the disorder of lipid metabolism and the development of IR [6-9]. Overproduction of mitochondrial reactive oxygen species (mitoROS) has been reported to elicit oxidative stress and consequently damages mitochondrial 
function in IR [10-12]. Interventions that scavenge mitoROS efficiently and simultaneously improve mitochondrial function and IR $[10,13]$.

Mitochondria are highly dynamic organelles that respond to and modulate cellular dynamics by continuously remodeling through fission, fusion, and autophagy. Emerging studies have identified mitochondrial dynamics as a novel mechanism involved in bioenergetic adaptation and mitoROS modulation. Inefficient mitochondrial respiration and exaggerated oxidative stress are characterized by a state of enhanced fission and mitigated fusion, while enhanced fusion is an important mechanism for the complementation of functional deficiencies via the sharing of soluble matrix contents [14, 15]. Defective mitochondrial dynamics has been suggested to participate in the pathogenesis of IR. It has been documented that mitochondrial fragmentation accompanied by suppressed Mitofusin 2 (Mfn2) expression occurs in obese or type 2 diabetes patients [16]. Consistently, specific Mfn2 repression is associated with decreased mitochondrial respiration and increased ROS production in skeletal muscle cells [14]. Mitophagy allows for the segregation and elimination of dysfunctional mitochondria and depends on constant fission-fusion activity [17]. Interplays between diminished mitochondrial dynamics and disturbed mitophagy have recently been indicated as causes of oxidative stress-induced declines of mitochondrial function in aging and IR [18].

Respiring mitochondria can intermittently generate mitochondrial flashes ("mitoflash"), reflecting quantal bursts of superoxide formation accompanying transient dissipation of the membrane potential and rapid depletion of the NADH along with a minor change in $\mathrm{pH}$ in the mitochondria $[19$, 20]. This novel mode of mitoROS production has been visualized by a protein biosensor, mt-cpYFP, and two ROS probes, MitoSOX and 2, 7-dichlorodihydrofluorescein diacetate [20, 21]. As a highly conserved universal mitochondrial activity, it occurs in isolated mitochondria, intact cells, ex vivo beating hearts, and living animals [19, 22-25]. While mitoflash activity is intimately interwoven with core mitochondrial functions (e.g., energy metabolism), it also constitutes a robust and sensitive responder to metabolic stress $[24,26]$, ischemiareperfusion injuries, and oxidative stress [19, 27, 28]. By in vivo imaging, we have recently shown that skeletal muscle mitoflash frequency responds to changes in whole-body metabolic state [22]. These recent advances provide an opportunity for further investigating the roles of mitochondria in the pathogenesis of metabolic diseases in the integrative environment of a living animal.

In the present study, we aimed, first, to establish a method for in vivo imaging of mitoflash in an animal model of IR. Then, we designed experiments to test the hypothesis that the mitoflash serves as a biomarker of IR stress, by tracking its response to disease progression and to clinically relevant treatment. In addition, we investigated the IR-associated mitoflash changes in the context of altered mitochondrial respiration, dynamics, and mitophagic signals. The overall goal was to provide novel investigative means and new insights, from the unique viewpoint of mitoflashes, for understanding the roles of mitochondria in the pathogenesis of metabolic diseases.

\section{Materials and methods}

Animals All procedures followed the principles of laboratory animal care of the National Academy of Sciences/National Research Council. db/m mice purchased from Jackson Laboratories (Bar Harbor, ME, USA) were cross mated with mtcpYFP transgenic mice [29] to generate mt-cpYFP $\mathrm{db} / \mathrm{m}$ and mt-cpYFP db/db mice. Twelve- and 34-week-old $\mathrm{db} / \mathrm{m}$ or $\mathrm{db} /$ $\mathrm{db}$ male mice with and without mt-cpYFP expression were used in the following experiments for characterization of a relatively early and late stage of IR during disease development.

Measurement of body weight, fasting blood glucose, and insulin After 4-6 h of fasting, mouse body weight was measured; blood samples were taken from the tail vein for blood glucose measurement, and glucose levels were measured by a portable glucometer (Roche); insulin levels in serum were measured by ELISA kit (Millipore).

Insulin tolerance test Mice were fasted for $4 \mathrm{~h}$, and insulin (Humulin ${ }^{\circledR}$ R, Eli Lilly) was injected intraperitoneally at $1 \mathrm{U} /$ $\mathrm{kg}$ body weight. Blood samples were taken from the tail vein at indicated time points for blood glucose measurement.

In vivo mitoflash detection by confocal microscopy The in vivo imaging technique was developed as described previously [22]. After 4-6 h of fasting, mice were anesthetized by pentobarbital sodium $(40 \mathrm{mg} / \mathrm{kg}$ body weight, i.p.), and an incision was made to expose the gastrocnemius muscle. During recording of mitoflashes, exposed muscle was immersed in isotonic balanced salt solution containing (in $\mathrm{mM}$ : 140 $\mathrm{NaCl}, 5 \mathrm{KCl}, 2.5 \mathrm{CaCl}_{2}, 2 \mathrm{MgCl}_{2}, 5.6 \mathrm{D}$-glucose, and 10 HEPES, $\mathrm{pH}$ 7.2). Dual wavelength excitation imaging of mtcpYFP was achieved by alternating excitation at 405 and $488 \mathrm{~nm}$ and detecting emission at $>505 \mathrm{~nm}$. Time-lapse images $(x y-t)$ were taken at $1-\mathrm{s}$ intervals.

In vivo imaging of mitochondrial connectivity with mitochondria-targeted photoactivatable green fluorescent protein For in vivo loading of tetramethylrhodamine methyl ester (TMRM), extracellular solution containing $500 \mathrm{nM}$ TMRM was applied to the exposed muscle. Regions of interest (ROIs) were photoactivated with an intense 405 -nm laser scanning beam for designated durations (typically $60 \mathrm{~ms}$ for an ROI of $1 \times 2 \mu \mathrm{m}$ ). Multi-track scanning was performed by 
exciting mitochondria-targeted photoactivatable green fluorescent protein (mt-PAGFP) at $488 \mathrm{~nm}$ and TMRM at $543 \mathrm{~nm}$, and fluorescence emission was collected at 505530 and $>560 \mathrm{~nm}$, respectively.

Image processing and mitoflash analysis Individual mitoflash was identified with the aid of custom-devised algorithms modified from Flashsniper [28], and their morphological and kinetic properties, including amplitude $\left(\Delta F / F_{0}\right.$, maximum fluorescence increase over baseline), full duration at half maximum (FDHM), and full area at half maximum (FAHM), were measured automatically.

Transmission electronic microscopy Transmission electronic microscopy (TEM) images were captured on an FEI Tecnai12 microscope at an accelerating voltage of $120 \mathrm{kV}$. A minimum of 10 micrographs from 4 to 6 mice were taken at $\times 12$, 000 or $\times 40,000$ magnification, and the mitochondrial perimeter was measured by software Image $\mathrm{J}$.

Pioglitazone treatment Pioglitazone (Pio) treatment was performed as previously described [30]. Briefly, Pio (Institute for Chemical Drug Control, Beijing, China) solubilized in $1.25 \%$ hydroxypropyl methylcellulose (HPMC) was administered to 8 -week-old mt-cpYFP $\mathrm{db} / \mathrm{db}$ mice by oral gavage (30 mg/kg body weight, once a day) for 28 days. As a treatment control, 8-week-old mt-cpYFP $\mathrm{db} / \mathrm{db}$ mice were gavaged with vehicle for 28 days.

Measurement of mitochondrial respiratory activity Mitochondrial respiratory activity was assessed as described previously [31]. Bioenergetic analyses of FDB myofibers were performed in an XF24 Extracellular Flux Analyzer (Seahorse Bioscience). Basal $\mathrm{O}_{2}$ consumption rates ( $\mathrm{pmol} / \mathrm{min}$ ) were recorded prior to and after sequential injections of oligomycin $(1 \mu \mathrm{M})$ and carbonyl cyanide 4-(trifluoromethoxy) phenylhydrazone (FCCP) $(1 \mu \mathrm{M})$ to induce maximal $\mathrm{O}_{2}$ consumption.

Western blot Gastrocnemius muscle tissue was homogenized in RIPA buffer supplemented with phosphatase inhibitors (Roche) and protease inhibitors (Sigma). The following primary mouse monoclonal antibodies were used: PGC1a (Millipore), $\beta$-actin (Sigma-Aldrich), Mfn2 (Sigma-Aldrich), Optic atrophy 1 (OPA1), dynamin-related protein 1 (Drp1) (BD Transduction Laboratories), and Parkin (Cell Signaling Technology). The rabbit polyclonal antibodies Mfn1 (Santa Cruz), p62 (Cell Signaling Technology), and LC3 (SigmaAldrich) were also used.

Statistical analysis Student's $t$ test or one-way or two-way analysis of variance (ANOVA) was applied to compare differences between groups when it is appropriate. GraphPad Prism (v5, GraphPad Software, La Jolla, CA, USA) was used for statistical analysis. Differences were considered statistically significant at $p<0.05$.

\section{Results}

In vivo imaging of mitoflashes in insulin-resistant skeletal muscle

To monitor mitoflash activity in the integrative milieu of IR animals, we cross mated mt-cpYFP transgenic mice with $\mathrm{db} /$ $\mathrm{m}$ mice, both on C57BL/6 genetic background. Briefly, mtcpYFP $\mathrm{db} / \mathrm{m}$ and mt-cpYFP $\mathrm{db} / \mathrm{db}$ offspring were identified by genotyping (Fig. 1a). In vivo confocal imaging was used to detect mitoflash signals in anesthetized transgenic mice. Fluorescence images of skeletal muscle confirmed the mitochondria-targeted expression of mt-cpYFP, giving rise to a striated pattern in the cells (Fig. 1b). Time-lapse images were exploited to record individual mitoflash and analyze their frequency, shape, and kinetics. A representative muscle mitoflash in an mt-cpYFP db/m mouse is shown in Fig. 1c. Typically, a mitoflash arose abruptly, peaked in $3 \mathrm{~s}$, and had an FDHM of $7.65 \pm 0.56 \mathrm{~s}$ (mean \pm SEM of 51 events from 4 mice, 6-20 skeletal muscle cells/mouse). The average fractional peak increase of mt-cpYFP fluorescence $\left(\Delta F / F_{0}\right)$ during a mitoflash was $0.31 \pm 0.03$ (mean \pm SEM of 51 events from 4 mice, 6-20 skeletal muscle cells/mouse), in agreement with previous reports [22].

Similar to the $\mathrm{db} / \mathrm{db}$ mice, mt-cpYFP $\mathrm{db} / \mathrm{db}$ mice displayed greater body weight, elevated blood glucose, and higher insulin levels when compared with their mt-cpYFP $\mathrm{db} / \mathrm{m}$ littermates (Fig. 1d). Insulin tolerance tests (ITTs) revealed that whole-body insulin sensitivity was clearly reduced at 12 weeks and was further blunted at 34 weeks in mt-cpYFP $\mathrm{db} / \mathrm{db}$ mice (Fig. 1e). Thus, the transgenic expression of mt-cpYFP did not alter the manifestation of obesity, glucose intolerance, and IR progression in the $\mathrm{db} / \mathrm{db}$ mice [32], validating the mt-cpYFP $\mathrm{db} / \mathrm{db}$ mouse as an IR model. These results laid the foundation for the use of mitoflashes in the investigation of possible disease-related mitochondrial dysfunction in living animals.

\section{Progressive increase of mitoflash frequency in mt-cpYFP db/db mice}

To determine whether and how mitoflash changes during the progression of IR, we acquired and characterized mitoflash events from mt-cpYFP $\mathrm{db} / \mathrm{m}$ and mt-cpYFP $\mathrm{db} / \mathrm{db}$ mice at 12 and 34 weeks of age (Fig. 2a). At 12 weeks, the rate of occurrence of mitoflashes showed a marginal but significant increase in $\mathrm{mt}-\mathrm{cpYFP} \mathrm{db} / \mathrm{db}$ mice, from $0.21 \pm 0.02 /$ $1000 \mu^{2} \cdot 100 \mathrm{~s}$ in mt-cpYFP db/m control mice ( $n=173$ files from 4 mice, $6-20$ skeletal muscle cells/mouse) to $0.32 \pm 0.03 /$ 


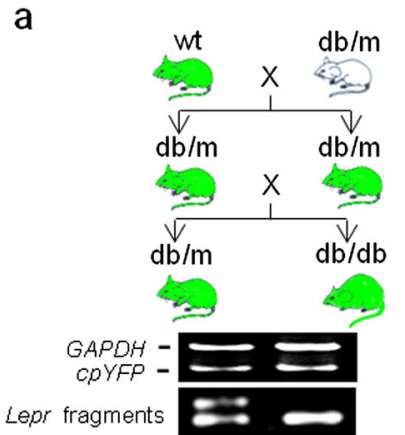

b

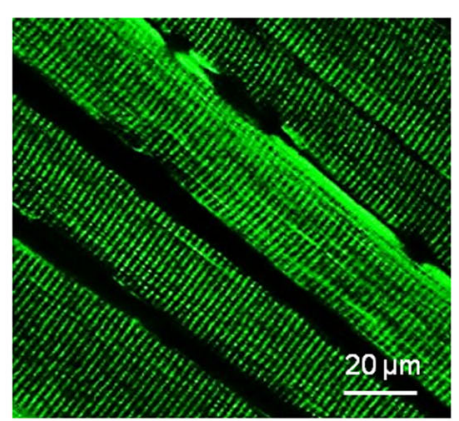

C

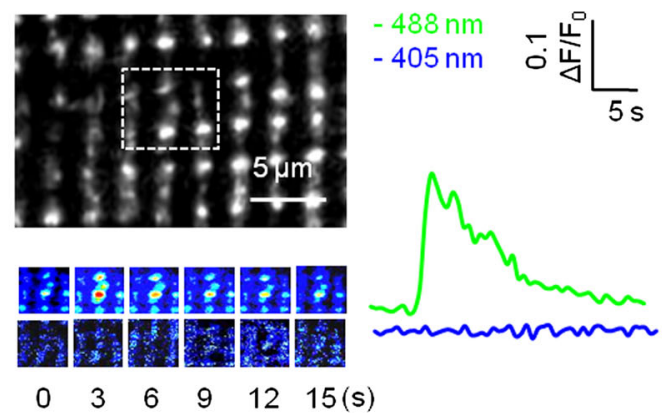

d

$\mathrm{adb} / \mathrm{m}$

$\mathrm{db} / \mathrm{db}$
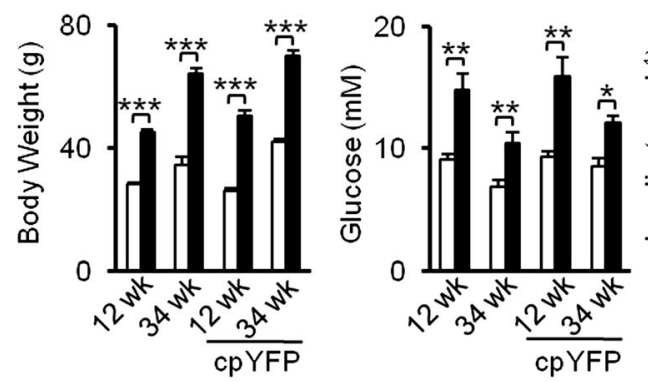

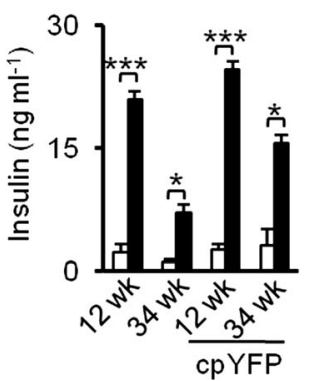

e

$\rightarrow-12 w k \mathrm{mt}-\mathrm{cp}$ YFP db/m

$\rightarrow-12 w \mathrm{kmt-cpYFP} \mathrm{db/db}$

$\rightarrow-34$ wk mt-cpYFP db/m $\rightarrow-34 \mathrm{wk}$ mt-cpYFP db/db

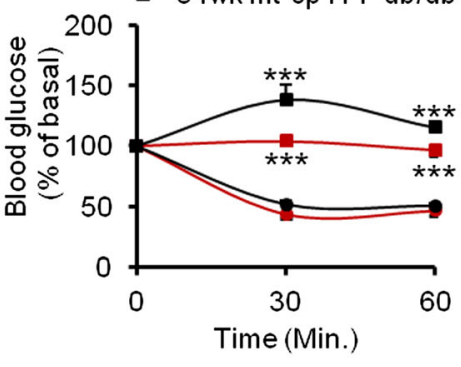

$\square m t-c p Y F P d b / m$

mt-cpYFP db/db

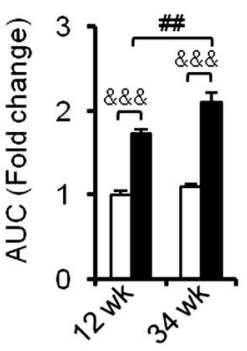

Fig. 1 Generation of mt-cpYFP-expressing IR mouse model for in vivo imaging of skeletal muscle mitoflashes during IR progression. a Crossbreeding scheme for the generation of mt-cpYFP $\mathrm{db} / \mathrm{db}$ mice and mt-cpYFP db/m controls. Green, mt-cpYFP expression. Bottom panels, PCR products of $m t-c p Y F P$ and restriction enzyme (RsaI) digestion fragments of the Lepr gene PCR product. b In vivo confocal imaging of skeletal muscle in anesthetized mice. Note the uniform expression of mtcpYFP in different muscle fibers and in different regions within a fiber. $\mathbf{c}$ Left panel, a typical punctiform mitoflash from a representative $\mathrm{db} / \mathrm{m}$ mouse. Dashed box on upper image highlights the flashing mitochondrion and its neighbors. Lower panels, time-lapse images of the mitoflash. Right panel, time courses of the mitoflash with 488- and 405-nm excitation. d Transgenic expression of mt-cpYFP did not alter the

$1000 \mu^{2} \cdot 100 \mathrm{~s}(n=240$ files from 7 mice, $7-25$ skeletal muscle cells/mouse), accompanied by overt obesity, hyperglycemia, hyperinsulinemia, and IR (Fig. 1d, e). At 34 weeks, the mitoflash frequency in mt-cpYFP $\mathrm{db} / \mathrm{db}$ mice was significantly increased compared to that at 12 weeks and was $243 \%$ higher than that in the age-matched mt-cpYFP $\mathrm{db} / \mathrm{m}$ control group (Fig. 2b).

For quantitative analysis of the properties of individual mitoflash, we performed ensemble averaging of their time course and parametric measurement of their morphology (Fig. 2c, d). At 12 weeks, the mitoflash from IR and control animals were virtually identical in terms of amplitude and time course. At 34 weeks, the amplitude remained unchanged while the kinetics of decay was moderately retarded (Fig. 2d), consistent with the notion that changes of mitoflash activity occur mainly in a frequency-modulated manner. Collectively, these in vivo data showed that mitoflash activity is mildly altered in the early phase of IR, but overt dysregulation develops during disease progression. typical phenotypes of obesity and insulin resistance in $\mathrm{db} / \mathrm{db}$ mice. Statistics of body weight (left panel), 4-6-h fasting blood glucose (middle panel), and serum insulin levels (right panel). e ITT tests showed reduced insulin sensitivity in mt-cpYFP $\mathrm{db} / \mathrm{db}$ mice in both age groups ( $n=6$ mice for each group), and the area under the curve (AUC; expressed as fold change vs 12 -week-old $\mathrm{mt}$-cpYFP $\mathrm{db} / \mathrm{m}$ ) indicated progressive insulin resistance at 34 weeks in mt-cpYFP $\mathrm{db} / \mathrm{db}$ mice. Data are expressed as mean \pm SEM. ${ }^{*} p<0.05,{ }^{*} * p<0.01,{ }^{*} * * p<0.001$ vs age-matched mt-cpYFP db/m mice; values were subject to Student's $t$ test. $\& \& \& p<0.001$ vs age-matched mt-cpYFP db/m mice, ${ }^{\# \#} p<0.01$ vs 12-week-old mt-cpYFP $\mathrm{db} / \mathrm{db}$ mice; values were subject to two-way ANOVA with Tukey's post hoc analysis

\section{Altered mitochondrial functional network reflected by mitoflash morphology in mt-cpYFP $\mathrm{db} / \mathrm{db}$ mice}

Apart from punctiform events each confined to a round or elliptic mitochondrion, arrays of neighboring mitochondria along the same or a few neighboring $Z$-lines can ignite and extinguish synchronously, giving rise to either a linear (length $>2 \mu \mathrm{m}$ ) or a lamellar ( $\geq 2$ sarcomeres) appearance of the mitoflash [22, 33]. These communal events might reflect physical interconnectivity among neighboring mitochondria, a notion supported by data from electron microscopy [34]. As such, mitoflash morphology affords a novel means to assess local mitochondrial networking.

Using an automated mitoflash detection algorithm [28], we classified mitoflashes into three categories - punctiform, linear, and lamellar - and measured the area. At 12 weeks, more lamellar mitoflashes were detected in mt-cpYFP $\mathrm{db} / \mathrm{db}$, and the histogram of the mitoflash area was shifted rightward, with network mitoflash events $\left(>10 \mu \mathrm{m}^{2}\right)$ twice as frequent as in 
a 12 wk mt-cpYFP db/m

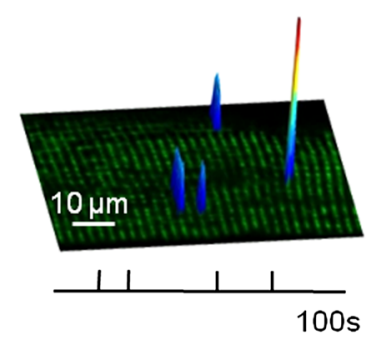

b

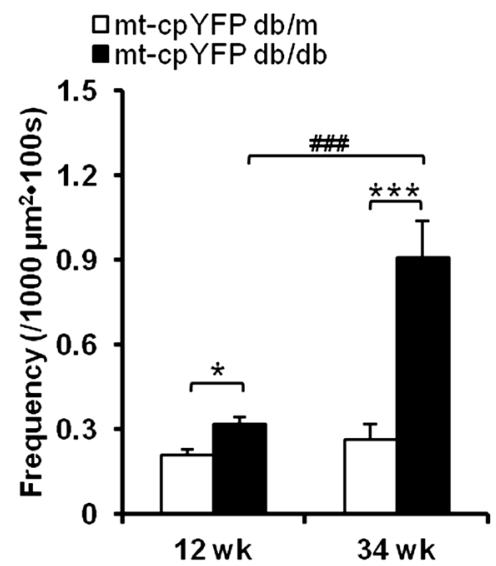

C
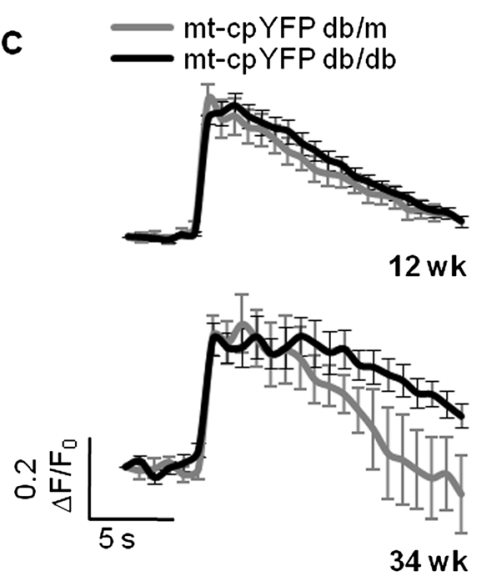

$34 \mathrm{wk} \mathrm{mt}-\mathrm{cpYFP} \mathrm{db} / \mathrm{m}$

2 wk mt-cpYFP db/db
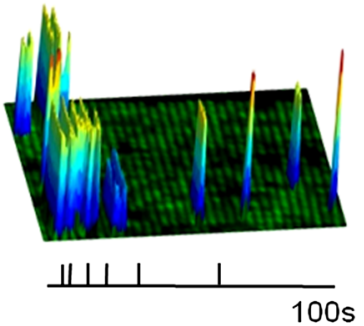

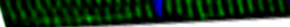

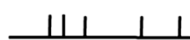

100 s
$34 w k m t-c p$ YFP db/db

d
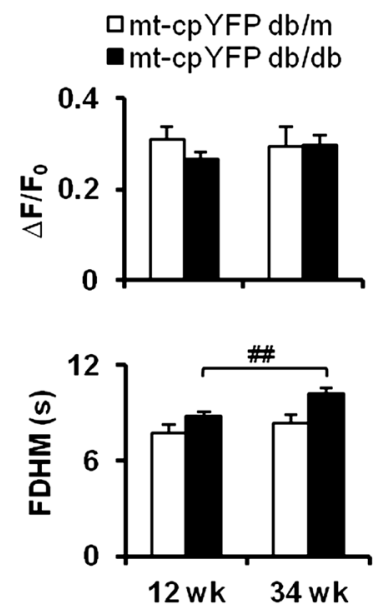

Fig. 2 Altered frequency and unitary properties of mitoflashes in IR skeletal muscle. a Surface plots of the frequency, amplitude, location, and spatial properties of mitoflashes in representative skeletal muscles from 12- and 34-week-old mt-cpYFP db/m and mt-cpYFP $\mathrm{db} / \mathrm{db}$ mice. Vertical ticks beneath the images mark the timing of these events during a 100 -s acquisition window. b Mitoflash frequency increased during disease progression in mt-cpYFP $\mathrm{db} / \mathrm{db}$ mice. c, $\mathbf{d}$ Ensemble-averaged time courses of mitoflashes (c) and quantitation of mitoflash amplitude $\left(\Delta F / F_{0}\right)$ and kinetics (full duration at half maximum, FDHM) (d). Data are expressed as mean \pm SEM. ${ }^{*} p<0.05,{ }^{* * *} p<0.001$ vs age-matched mtcpYFP db/m mice; ${ }^{\#} p<0.01,{ }^{\# \#}<0.001$ vs 12 -week-old mt-cpYFP db/ $\mathrm{db}$ mice; values were subject to two-way ANOVA with Tukey's post hoc analysis

initial enhancement of local mitochondrial networking, sustained IR stress causes fragmentation such that small but more frequent punctiform mitoflashes dominate.

That IR stress promotes mitochondrial fission and fragmentation is in general agreement with reports by several groups $[14,16,35]$. However, that IR stress initially promotes local mitochondrial networking, suggestive of enhanced physical and functional communication among mitochondria, came as a surprise. To gain independent support, we used mt-PAGFP, which has been frequently used to reveal mitochondrial interconnection changes [36]. In mt-PAGFPexpressing skeletal muscle, we detected a 40 -fold increase in local mt-PAGFP fluorescence upon 60-ms illumination with a 405-nm laser, while the TMRM staining, which co-localized with photoactivated mt-PAGFP and reflects the mitochondrial membrane potential [36], remained unchanged. Notably, not all photoactivated mt-PAGFP signals were confined to sites of laser illumination (Fig. 3g); rather, it spread along the $Z$-line and even across two or more sarcomeres. The average area of the mt-PAGFP signal was $5.06 \pm 0.17 \mu^{2}{ }^{2}(n=108$ files from 4 mice, 5-7 skeletal muscle cells/mouse, average observation area $=3255.7 \pm 135.7 \mu \mathrm{m}^{2} /$ cell $)$ in $\mathrm{db} / \mathrm{m}$ mice and was $56.7 \mathrm{\mu m}^{2} /$ cell, $p<0.001$ vs control) (Fig. 3d-f). Thus, after 

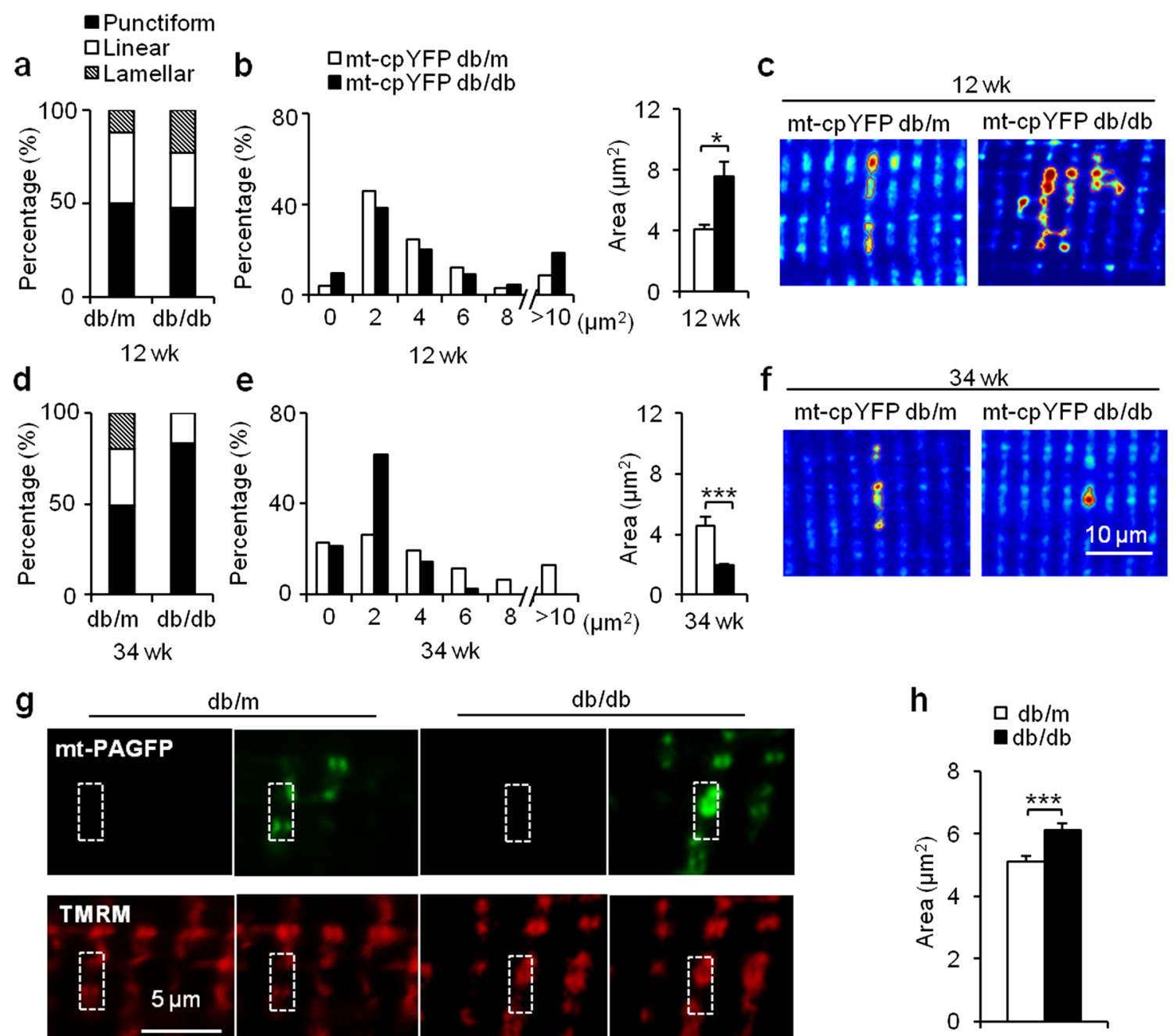

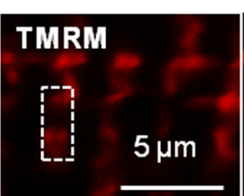

Pre

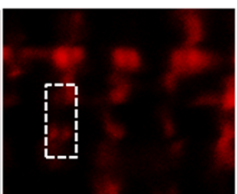

$1 \mathrm{Min}$

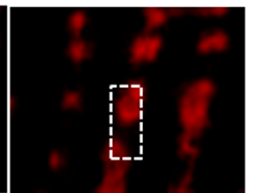

$1 \mathrm{Min}$.
Fig. 3 Biphasic changes of spatial properties of mitoflashes during IR progression. a-f Using an automated mitoflash detection algorithm, the proportions of punctiform, linear (length $>2 \mu \mathrm{m}$ ), and lamellar ( $\geq 2$ sarcomeres) mitoflashes were quantified $(\mathbf{a}, \mathbf{d})$, and mitoflash areas were measured in different groups $(\mathbf{b}, \mathbf{e})$. Note that average mitoflash size was enlarged at 12 weeks (upper panel) and diminished at 34 weeks in mt-cpYFP db/db group (lower panel). Representative images show mitoflashes of punctiform (bottom right), linear (top left and bottom left), and lamellar shapes (top right). Contours delineating mitoflash boundaries were generated automatically by the flash detection algorithm $(\mathbf{c}, \mathbf{f})$. g Hyper-connectivity of local mitochondrial networking in early IR was confirmed by the spatial spreading of photoactivated mtPAGFP (upper images). A pair of images of the same region was taken immediately before (Pre) and $1 \mathrm{~min}$ after photoactivation. Note that mtPAGFP signals co-localized with TMRM and spread beyond the region of photoactivation. h Average area of photoactivated mt-PAGFP was increased in skeletal muscle of 12-week-old $\mathrm{db} / \mathrm{db}$ mice compared to that in $\mathrm{db} / \mathrm{m}$ mice. Data are expressed as mean \pm SEM. ${ }^{*} p<0.05$, ${ }^{* *} p<0.01,{ }^{* * *} p<0.001$ vs age-matched mt-cpYFP $\mathrm{db} / \mathrm{m}$ or $\mathrm{db} / \mathrm{m}$ mice; values were subject to Student's $t$ test

we next used TEM to complement the optical fluorescent imaging approach. In control mice at 12 weeks, most mitochondria were spheroid or bean shaped and appeared at the dyads of $Z$-lines. A small proportion of elongated tubular mitochondria were also observed. In mt-cpYFP $\mathrm{db} / \mathrm{db}$ mice, congruent with increased communal mitoflash activity and area, more elongated tubular and irregularly shaped mitochondria with an increased perimeter were seen (Fig. $4 \mathrm{a}, \mathrm{b}$ ).

In comparison, elongated mitochondria were found at a slightly higher frequency in muscle from 34-week-old mt$\mathrm{cpYFP} \mathrm{db/m} \mathrm{mice.} \mathrm{However,} \mathrm{elongated,} \mathrm{interconnected,} \mathrm{tubu-}$ lar mitochondria were rarely observed in 34 -week-old mt- 
Fig. 4 TEM micrographs of mitochondrial networking changes in IR skeletal muscle. Representative TEM micrographs in (a) and (c) show altered mitochondrial morphology and networking in skeletal muscles of 12- and 34-week-old mt-cpYFP $\mathrm{db} / \mathrm{db}$ mice compared to mtcpYFP db/m littermates. Left, $\times 12,000$; right $, \times 40,000$. Statistics of perimeters of mitochondria in TEM micrographs in (b) and (d) show enlargement and enhanced connectivity at 12 weeks followed by fragmentation at 34 weeks ( $n=$ 4 mice for each group). Data are expressed as mean \pm SEM.

$* * * p<0.001$ vs age-matched mtcpYFP $\mathrm{db} / \mathrm{m}$ mice; values were subject to Student's $t$ test a

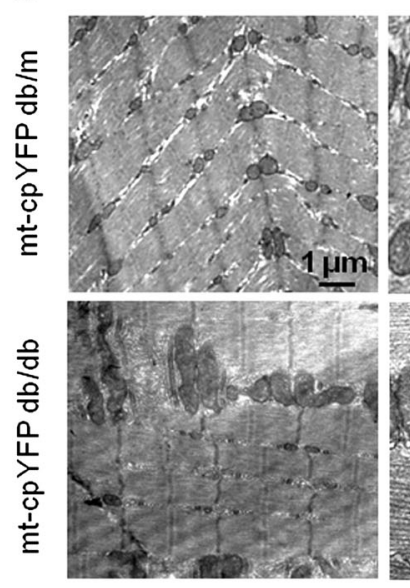

c

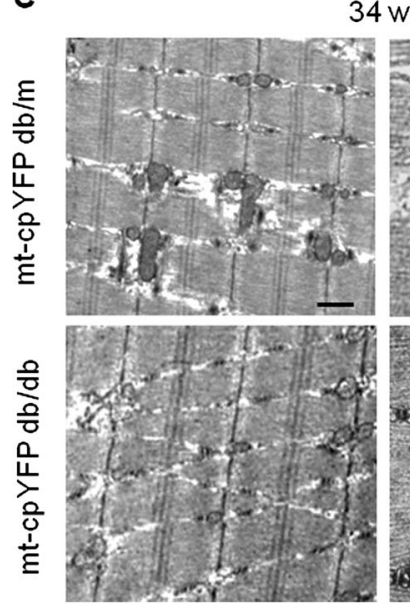

12 wk

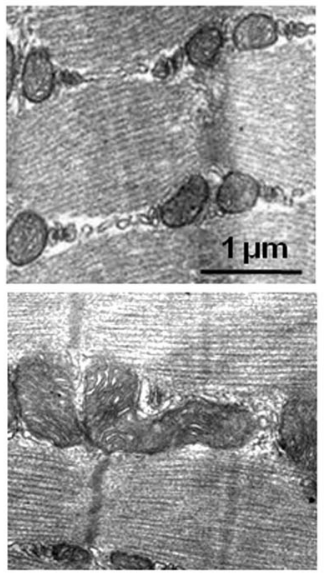

34 wk

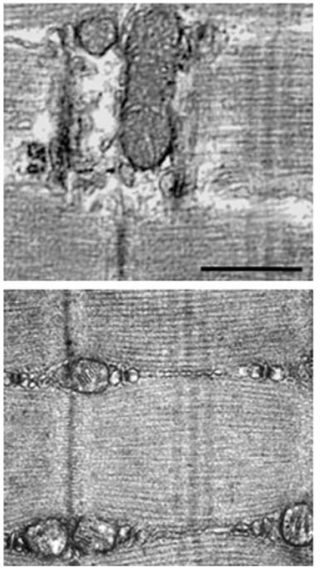

b

$\square m t-c p Y F P ~ d b / m$

mt-cpYFP db/db

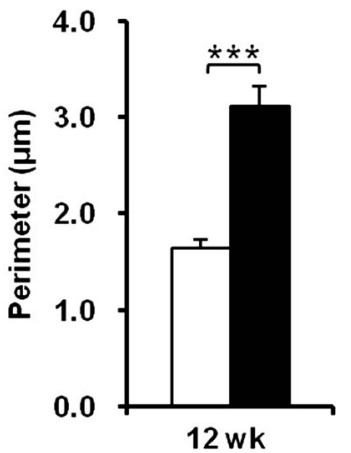

d

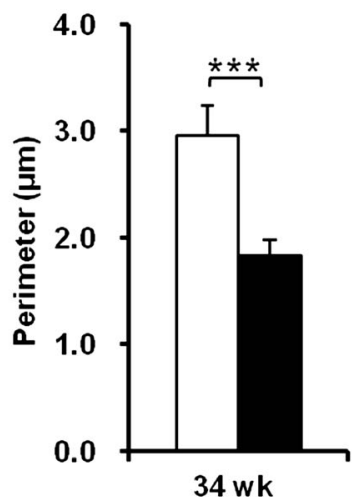

cpYFP $\mathrm{db} / \mathrm{db}$ mice. Instead, most of the mitochondria were smaller, and the averaged mitochondrial perimeter seen in TEM micrographs was significantly decreased (Fig. 4c, d). In conjunction with confocal imaging of mitoflash shape and local mt-PAGFP diffusion, these finding revealed a biphasic change in mitochondrial networking at different stages of disease in the IR mouse model.

\section{Altered expression of proteins for mitochondrial dynamics and quality control during the progression of insulin resistance}

We next investigated the possible molecular basis of these morphologic changes at different stages in the development of IR. We found that the levels of Mfn2 and Mfn1, which promotes mitochondrial fusion, were significantly increased at 12 weeks, coincident with enhanced mitochondrial networking and enlargement at that time. However, these upregulations disappeared at 34 weeks, when fragmentation of mitochondrial network was evident. Pro-fission protein Drp1 only manifested a significant reduction at 34 weeks (Fig. 5a, b).
It has been shown that mitochondrial dynamics also contribute to mitochondrial quality control through mitophagy, and inhibition of either Mfn2 or Drp1 leads to deficient turnover and dysfunction $[37,38]$. During mitophagy, cytosolic Parkin targets and translocates to depolarized mitochondria [39]. The autophagy adaptor p62 is recruited [40] and further binds to microtubule-associated protein-1 light chain II (LC3 II), which is the autophagosome-associated form of LC3. Subsequently, LC3 II entrapped inside autophagosomes is degraded [41]. Investigation of molecules involved in the mitophagy pathway revealed that p62 and Parkin protein levels were decreased in mt-cpYFP db/db mice. Meanwhile, a significant accumulation of LC3II was found in these mice at 34 weeks, suggesting an accumulation of autolysosomes. These results indicated that mitophagy is markedly retarded in mt-cpYFP $\mathrm{db} / \mathrm{db}$ mice at 34 weeks (Fig. 5c, d). Concomitant with this, mitochondrial respiratory function was diminished as evidenced by the reduced expression of $\mathrm{PGC} 1 \alpha$, which largely controls mitochondrial oxidative phosphorylation [42], and maximal respiratory capacity in mt-cpYFP $\mathrm{db} / \mathrm{db}$ mice (Fig. 5e, f), along with the reduction of mitoflash area and exaggerated mitochondrial networking fragmentation. Taking 

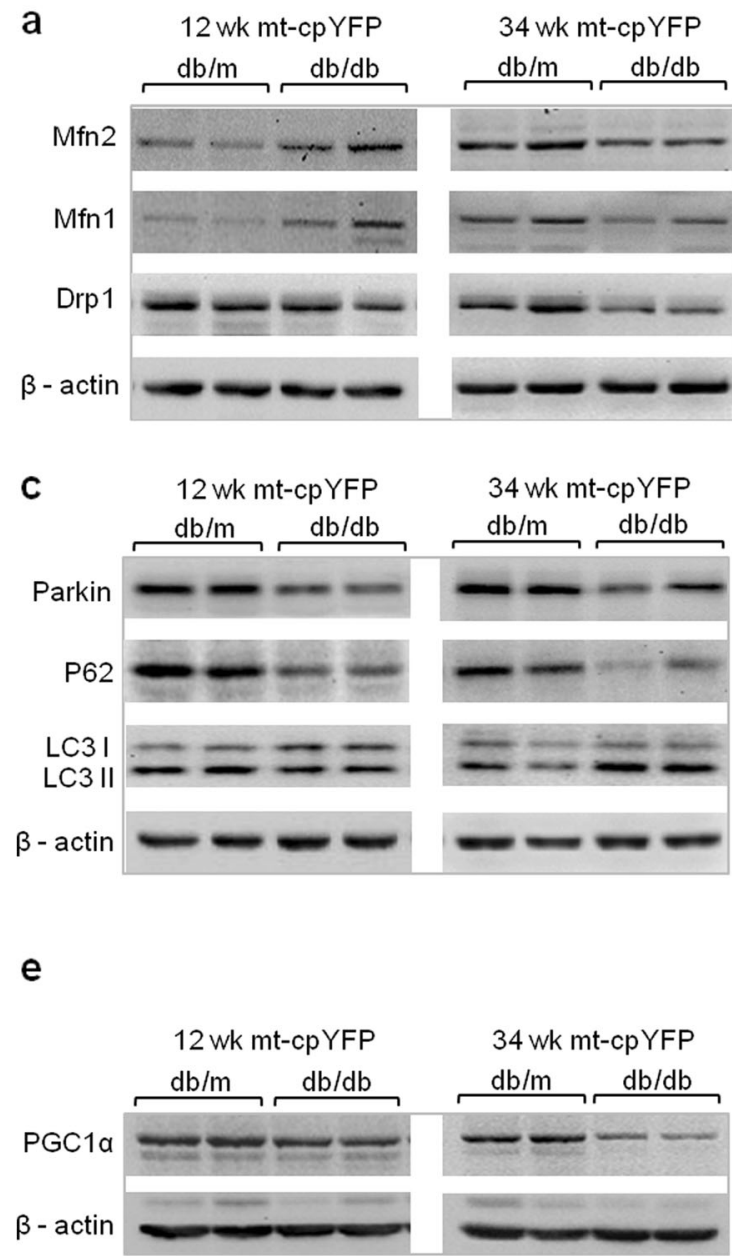

Fig. 5 Altered expression of proteins for mitochondrial dynamics and mitophagy, and deficient mitochondrial respiration in IR skeletal muscle. a-d Representative Western blots (a, c) and statistics $(\mathbf{b}, \mathbf{d})$ show that the expression of essential proteins involved in mitochondrial dynamics and quality control changed during IR progression; values were recorded as fold change vs age-matched mt-cpYFP db/m littermates ( $n=4-6$ mice). e Representative Western blots and statistics show that the expression of master regulator of mitochondrial oxidative phosphorylation, $\mathrm{PGC} 1 \alpha$. Values were recorded as fold change vs age-matched mt-cpYFP $\mathrm{db} / \mathrm{m}$ littermates ( $n=4-6$ mice). f Using the XF24 Extracellular Flux Analyzer (Seahorse Bioscience), isolated FDB muscles from each

together the data from molecular profiling, ultrastructural analysis, and mitoflash measurement, we conclude that IR stress causes characteristic compensatory responses in the mitochondria at 12 weeks that proceed to a decompensated state at 34 weeks in mt-cpYFP $\mathrm{db} / \mathrm{db}$ mice.

\section{Reversal of altered mitoflash activity and respiratory function in pioglitazone-treated mt-cpYFP $\mathrm{db} / \mathrm{db}$ mice}

The data thus far suggested that mitoflash activity may serve as a sensitive and robust biomarker of IR stress and disease b $\square \mathrm{mt}-\mathrm{cpYFP} \mathrm{db/m}$

- $\mathrm{mt}-\mathrm{cp} Y F P \mathrm{db} / \mathrm{db}$ Mfn2

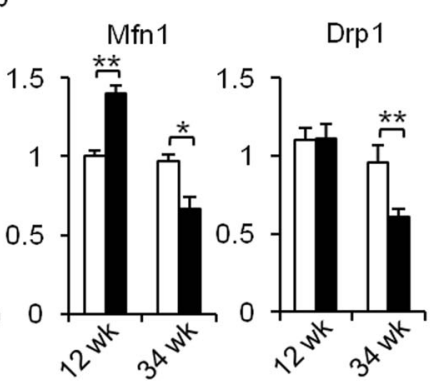

d Dmt-cpYFP db/m

- $m t-c p Y F P d b / d b$
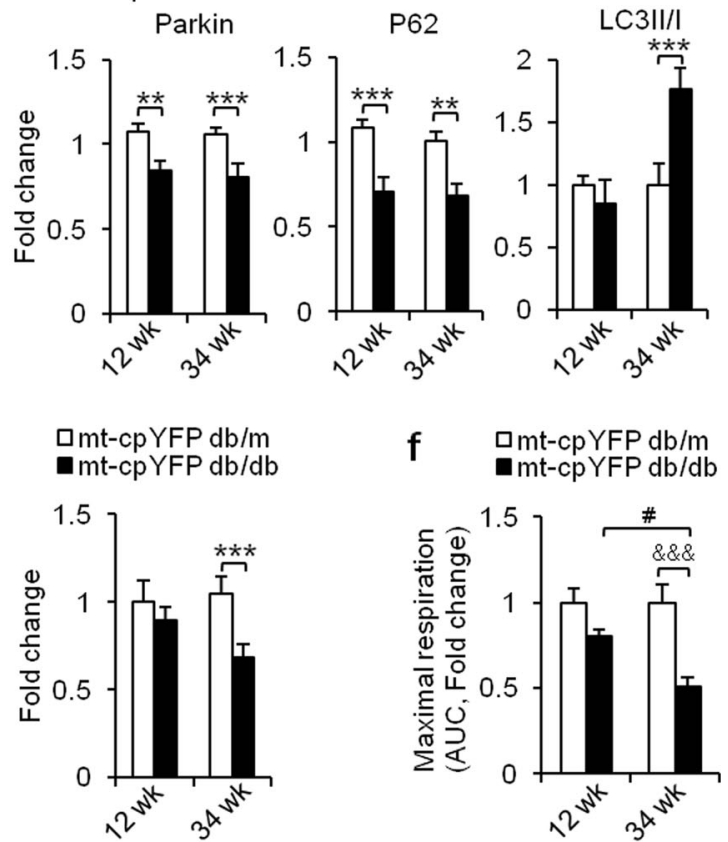

group were sequentially treated with oligomycin $(1 \mu \mathrm{M})$ and FCCP $(1 \mu \mathrm{M})$ to assess the maximal respiration capacity of mitochondria. Area under curves of $\mathrm{O}_{2}$ consumption rates were calculated for comparison among groups. Values were recorded as fold change vs 12week-old $\mathrm{mt}$-cpYFP db/m littermates ( $n=4$ mice for each group). Data are expressed as mean \pm SEM. $* p<0.05, * * p<0.01, * * * p<0.001$ vs agematched mt-cpYFP $\mathrm{db} / \mathrm{m}$ mice; values were subject to Student's $t$ test. $\& \& \& p<0.001$ vs age-matched mt-cpYFP db/m, ${ }^{\#} p<0.05$ vs 12 -week-old mt-cpYFP db/db; values were subject to two-way ANOVA with Tukey's post hoc analysis

progression. In particular, mitoflash appeared to reflect both the metabolic status and the local networking of mitochondria. To test this hypothesis, we examined the mitochondrial responses to clinically relevant treatment of IR.

Pioglitazone (Pio) is one of the thiazolidinediones (TZDs) that are commonly used to treat metabolic syndrome and type 2 diabetes in clinical practice [43]. A previous study has shown that rosiglitazone, another TZDs, upregulates the expression of genes involved in mitochondrial biogenesis and changes the mitochondrial structure in the adipose tissue of $\mathrm{db} / \mathrm{db}$ mice $[44,45]$. In obese IR mice, Pio ameliorates IR in 
the skeletal muscle [30]. In 12-week-old mt-cpYFP $\mathrm{db} / \mathrm{db}$ mice, ITT confirmed the efficacy of Pio in restoring wholebody insulin sensitivity (Fig. 6a). Molecular profiling revealed that Mfn2 and Mfn1 were downregulated, and Drp1 was unchanged, all these dynamics-related proteins returning to or remaining at control levels (Fig. 6b, c). In terms of mitophagy-related signaling, the expression of Parkin, p62, and LC3II were also normalized (Fig. 6d, e). Functionally, the maximal mitochondrial respiration was increased by $26.4 \%$ after Pio treatment compared to the vehicle-treated group (Fig. 6f). These results suggested that Pio treatment ameliorates the alterations in mitochondrial function, dynamics, and morphology, in good agreement with the notion that TZDs help to preserve mitochondrial function and structure in IR.

More importantly, we found that Pio treatment significantly decreased mitoflash frequency by $33.3 \%$, to a level comparable to that in mt-cpYFP db/m mice (Fig. $6 \mathrm{~g}, \mathrm{~h}$ ). Furthermore, the increases in mitoflash size and FDHM associated with early IR were also initially reversed after Pio treatment (Fig. 6i, j), indicating the restoration of mitochondrial metabolism and local networking. Thus, the changes in mitoflash activity and unitary properties as well as changes in mitochondrial functions, dynamics, and the quality-control machinery were essentially normalized with the reversal of IR and associated stresses. In addition, these results strongly support the notion that mitoflash can be exploited as a novel biomarker to gauge metabolic disease progression and therapeutic efficacy in living animals.

\section{Discussion}

In this study, we have characterized, for the first time, mitoflash changes in the IR mt-cpYFP transgenic mouse model. We dissected the alterations of mitoflash characteristics with IR development and documented the mitoflash response to therapeutic intervention. The main finding was that mitoflash can serves as a unique biomarker of diseaseassociated stress in the $\mathrm{db} / \mathrm{db}$ mouse model of IR. Specifically, mitoflash frequency was mildly increased early in IR at 12 weeks and was overtly elevated at 34 weeks. This progressive increase in mitoflash frequency occurred in parallel with the impairment of mitochondrial respiration and deterioration of mitophagic signaling. The latter was indexed by sustained decreases of Parkin and p62 expression and an increase of LC3II accumulation, indicating repressed mitophagic flux. More importantly, we found that treatment of Pio, one of the commonly used TZDs, effectively reversed the mitoflash responses, while restoring insulin sensitivity in the relatively early stage of IR. Pio treatment also simultaneously normalized mitochondrial respiration, local mitochondrial networking, and the expression of major proteins mediating mitochondrial dynamics and quality control. Taken together, these lines of evidence strongly support our hypothesis that the mitoflash is a biomarker which gauges the state of disease progression as well as the efficacy of therapeutic intervention.

The above findings fit well with the prevalent view that the mitochondrion is central to the development of many types of metabolic diseases. Cumulative metabolic stress has been suggested to be involved in oxidative stress-induced IR. As the main site of cellular energy metabolism, the mitochondrion is the first-line sensor of and defender against metabolic stressors. Moreover, metabolic stress is often interlinked with oxidative stress - increased access to lipid, glucose, and insulin is known to exacerbate oxidative stress [46, 47]. This is because, in the process of energy metabolism, the mitochondria generate superoxide anions as the precursor of other types of ROS and also enzymes for antioxidant defense. Hence, mitochondria are also the first-line sensor of and defender against diverse oxidative stresses. Indeed, previous in vitro and in vivo experiments have shown that glucose and insulin acutely stimulate mitoflash activity in the skeletal muscle [19, 46] and basal ROS production also contributes to mitoflash ignition [26]. The present results indicate that the mitoflash machinery is also a point of convergence for IR-associated metabolic and oxidative stresses, and optical measurement of mitoflash affords a novel means for the investigation of the mitochondrial stress response in living animals.

The monophasic increase of mitoflash frequency during IR progression was in sharp contrast to the biphasic change of local mitochondrial networking, as revealed by mitoflash area, the spread of mt-PAGFP, and TEM data. The latter was manifested as hyperconnectivity and enlargement of mitochondria at 12 weeks and eventual mitochondrial networking fragmentation at 34 weeks. Functionally, mitochondrial dynamics exert a significant impact on adaptation to altered metabolic states. Mitochondrial fusion helps to maximize the fidelity of oxidative respiration by complementation among mitochondria $[15,48]$, and fragmentation by fission or disconnection severely compromises it. In this scenario, we propose that transiently enhanced local mitochondrial networking at 12 weeks constitutes a compensatory mechanism, whereas eventual mitochondrial networking fragmentation at 34 weeks reflects a detrimental consequence of the IR stress, which may drive disease progression in a vicious cycle. Similar to our observation in 34-week-old mt-cpYFP db/db mice, it is reported that mitochondrial dynamics of skeletal muscle was impaired in long-term HFD (40 weeks) induced obese mice [49]. This interpretation is further supported by the finding that Pio treatment, while normalizing insulin sensitivity, effectively reversed the change in local mitochondrial networking.

Mechanistically, we provide evidence that major mediators in the mitochondrial fusion-fission machinery may be responsible for the biphasic changes of local mitochondrial networks in IR $\mathrm{db} / \mathrm{db}$ mice. In particular, there were similar biphasic 
a

$\longrightarrow$ Veh.mt-cp YFP db/m

$\rightarrow-V e h$. mt-cp YFP db/db

$\rightarrow-$ Pio. mt-cpYFP db/db

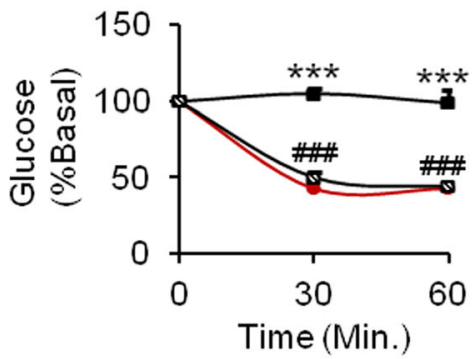

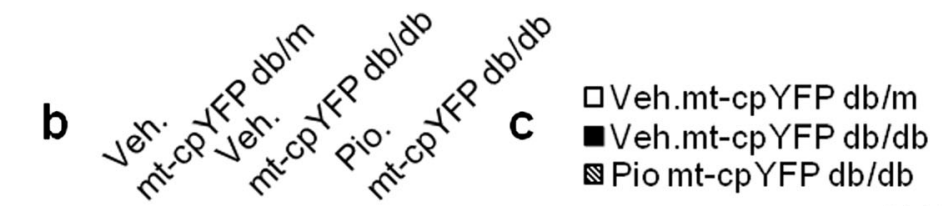

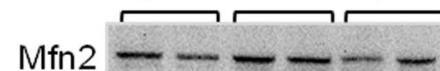

Mfn1

Drp1

$\beta$-actin

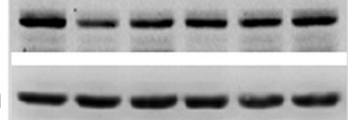

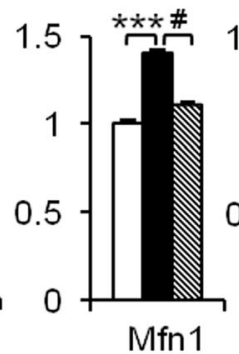

Mfn1

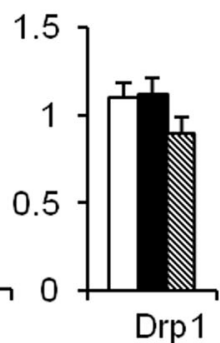

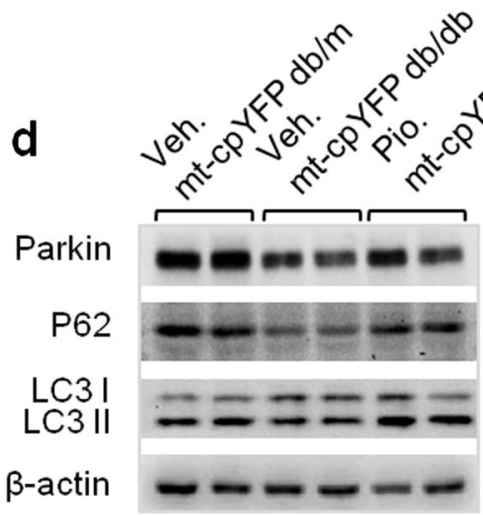

口Veh.mt-cpYFP db/m

e Veh.mt-cpYFP db/db

$\mathbb{Q}$ Pio.mt-cp YFP $d b / d b$
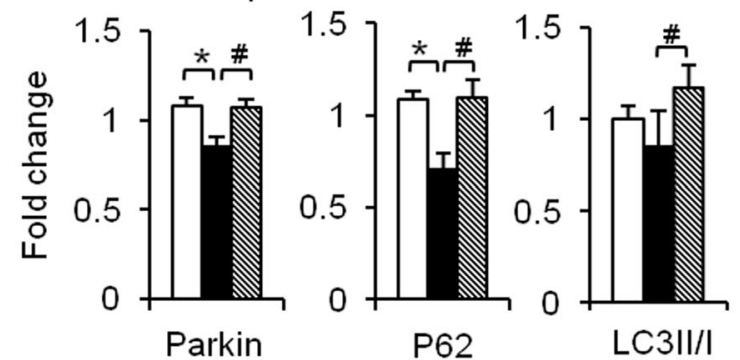

\section{口Veh. mt-cpYFP db/m \\ f Veh.mt-cpYFP db/db \\ $\mathbb{\mathbb { N } P i o}$. mt-cpYFP db/db}

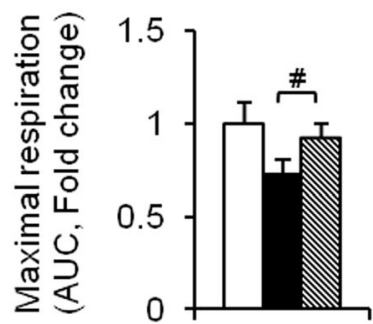

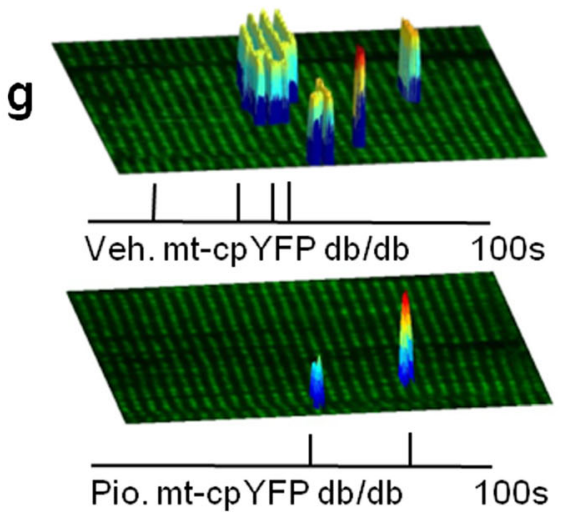

Fig. 6 Pioglitazone treatment normalizes mitochondrial structure, respiratory function, and mitoflash activity while restoring insulin sensitivity. a In 12-week-old mt-cpYFP db/db mice, systemic insulin sensitivity was restored by pioglitazone (Pio) as indicated by the insulin tolerance test in vehicle (Veh)- and Pio-treated mt-cpYFP db/db mice $(n=$ 6 mice for each group). b-e Pio effects on expression of Mfn2, Mfn1, Drp1, Parkin, p62, and LC3 in skeletal muscle; values were recorded as fold change vs Veh-treated mt-cpYFP $\mathrm{db} / \mathrm{m}$ littermates $(n=4$ mice for each group). f Maximal mitochondrial respiration was significantly

changes in Mfn2 and Mfn1, which promotes mitochondrial fusion, increasing at 12 weeks followed by a decrease at 34 weeks. The result is consistent with the mitochondrial improved. Area under curves of $\mathrm{O}_{2}$ consumption rates were calculated for comparison among groups. Values were recorded as fold change vs Veh-treated mt-cpYFP db/m littermates ( $n=4$ mice for each group). $\mathbf{g}$-j Typical images (g) and statistics of Pio effects on mitoflash frequency (h), spatial area (i), and FDHM (j) ( $n=4-8$ mice for each group). Data are expressed as mean \pm SEM. ${ }^{*} p<0.05, * * * p<0.001$ vs Veh-treated $\mathrm{db} / \mathrm{m}$ mice, ${ }^{\#} p<0.05,{ }^{\#} p<0.01,{ }^{\# \#} p<0.001$ vs Veh-treated db/db mice; values were subject to one-way ANOVA with Tukey's post hoc analysis

networking fragmentation and decreased Mfin 2 expression in muscles from patients with type 2 diabetes and obese humans [16]. However, it is opposite to the prediction from reduced 
Drp1 expression at 34 weeks, which would repress mitochondrial fission and fragmentation. At this time point, the suppressive effects of Mfn2 appear to be dominant in the interplay among different mediators of mitochondrial dynamics.

By in vivo imaging skeletal muscle in a newly established biosensor-expressing $\mathrm{db} / \mathrm{db}$ mouse model, we demonstrated a progressive increase of mitoflash frequency during IR and its reversal by Pio treatment in relatively early IR. We also uncovered that, prior to networking fragmentation, there was a transient, Pio-reversible enhancement of local mitochondrial networking in early IR, arising from changes in mediators of mitochondrial dynamics and quality control. These findings support a concept that mitoflash can be used as the optical readout of mitochondrial function and its stress response, gaining unique insights into free radical formation and energy metabolism as well as mitochondrial dynamics, radical formation, energy metabolism as well as mitochondrial dynamics. In addition, the in vivo imaging methods allow for multiple observations in single animals, which enhance the resolution of mitochondrial functional changes during disease progression. Collectively, our findings support a central role of the mitochondria in the pathogenesis of metabolic disease and suggest that mitoflash may serve as a unique biomarker to gauge IR stresses and their amelioration by therapeutic interventions.

\begin{abstract}
Acknowledgments The authors thank Dr. Iain C. Bruce (Institute of Molecular Medicine, Peking University), for his help with editing English; Drs Ruiping Xiao, Chunmei Cao, Ruisheng Song, and Yan Zhang (Institute of Molecular Medicine, Peking University) for their scientific discussion and critical comments; and Mr. Hui Wang, Mr. Jun Zhang, and Ms. Yuli Liu (Institute of Molecular Medicine, Peking University) for their technical support.

This study was supported by the National Key Basic Research Program of China (2013CB531200 and 2011CB809100); the National Natural Science Foundation of China (81270883, 31130067, 30870996, 81471063, 31221002, and 31123004); and the National Science and Technology Major Projects grant for "Major New Drugs Innovation and Development" 2013ZX09508104.
\end{abstract}

Conflict of interest The authors declare that they have no conflict of interests.

\begin{abstract}
Authorship statement Y.D. contributed to the study design, experimentation, data analysis and interpretation, and manuscript writing. H.F., W.S., Y.X., N.H., L.P., and X.S. contributed to the experiments. T.S. contributed to the data analysis. J.Z., X.W., and Q.M. contributed to the discussion and methodological development, and revised the manuscript. H.C. and X.Z. conceived and supervised the study, interpreted the results, and wrote the manuscript. X.Z. is the guarantor of this study and, as such, had full access to all the data in the study and takes responsibility for the integrity of the data and the accuracy of the data analysis.
\end{abstract}

Open Access This article is distributed under the terms of the Creative Commons Attribution 4.0 International License (http:// creativecommons.org/licenses/by/4.0/), which permits unrestricted use, distribution, and reproduction in any medium, provided you give appropriate credit to the original author(s) and the source, provide a link to the Creative Commons license, and indicate if changes were made.

\section{References}

1. Eckel RH, Grundy SM, Zimmet PZ (2005) The metabolic syndrome. Lancet 365:1415-1428

2. Reaven GM (1995) Pathophysiology of insulin resistance in human disease. Physiol Rev 75:473-486

3. Song R, Peng W, Zhang Y, Lv F, Wu HK, Guo J, Cao Y, Pi Y, Zhang X, Jin L et al (2013) Central role of E3 ubiquitin ligase MG53 in insulin resistance and metabolic disorders. Nature 494: 375-379

4. Perseghin G, Scifo P, De Cobelli F, Pagliato E, Battezzati A, Arcelloni C, Vanzulli A, Testolin G, Pozza G, Del Maschio A et al (1999) Intramyocellular triglyceride content is a determinant of in vivo insulin resistance in humans: a $1 \mathrm{H}-13 \mathrm{C}$ nuclear magnetic resonance spectroscopy assessment in offspring of type 2 diabetic parents. Diabetes 48:1600-1606

5. Szczepaniak LS, Babcock EE, Schick F, Dobbins RL, Garg A, Burns DK, McGarry JD, Stein DT (1999) Measurement of intracellular triglyceride stores by $\mathrm{H}$ spectroscopy: validation in vivo. Am J Physiol 276:E977-E989

6. Kelley DE (2005) Skeletal muscle fat oxidation: timing and flexibility are everything. J Clin Invest 115:1699-1702

7. Morino K, Petersen KF, Shulman GI (2006) Molecular mechanisms of insulin resistance in humans and their potential links with mitochondrial dysfunction. Diabetes 55(Suppl 2):S9-S15

8. Petersen KF, Befroy D, Dufour S, Dziura J, Ariyan C, Rothman DL, DiPietro L, Cline GW, Shulman GI (2003) Mitochondrial dysfunction in the elderly: possible role in insulin resistance. Science 300:1140-1142

9. Samuel VT, Shulman GI (2012) Mechanisms for insulin resistance: common threads and missing links. Cell 148:852-871

10. Anderson EJ, Lustig ME, Boyle KE, Woodlief TL, Kane DA, Lin CT, Price JW 3rd, Kang L, Rabinovitch PS, Szeto HH et al (2009) Mitochondrial $\mathrm{H} 2 \mathrm{O} 2$ emission and cellular redox state link excess fat intake to insulin resistance in both rodents and humans. J Clin Invest 119:573-581

11. Bonnard C, Durand A, Peyrol S, Chanseaume E, Chauvin MA, Morio B, Vidal H, Rieusset J (2008) Mitochondrial dysfunction results from oxidative stress in the skeletal muscle of diet-induced insulin-resistant mice. J Clin Invest 118:789-800

12. Hoeks J, Briede JJ, de Vogel J, Schaart G, Nabben M, MoonenKornips E, Hesselink MK, Schrauwen P (2008) Mitochondrial function, content and ROS production in rat skeletal muscle: effect of high-fat feeding. FEBS Lett 582:510-516

13. Kim JA, Wei Y, Sowers JR (2008) Role of mitochondrial dysfunction in insulin resistance. Circ Res 102:401-414

14. Sebastian D, Hernandez-Alvarez MI, Segales J, Sorianello E, Munoz JP, Sala D, Waget A, Liesa M, Paz JC, Gopalacharyulu P et al (2012) Mitofusin 2 (Mfn2) links mitochondrial and endoplasmic reticulum function with insulin signaling and is essential for normal glucose homeostasis. Proc Natl Acad Sci U S A 109:55235528

15. Liesa M, Shirihai OS (2013) Mitochondrial dynamics in the regulation of nutrient utilization and energy expenditure. Cell Metab 17: 491-506

16. Bach D, Naon D, Pich S, Soriano FX, Vega N, Rieusset J, Laville M, Guillet C, Boirie Y, Wallberg-Henriksson H et al (2005) Expression of Mfn2, the Charcot-Marie-Tooth neuropathy type 2A gene, in human skeletal muscle: effects of type 2 diabetes, obesity, weight loss, and the regulatory role of tumor necrosis factor alpha and interleukin-6. Diabetes 54:2685-2693

17. Twig G, Elorza A, Molina AJ, Mohamed H, Wikstrom JD, Walzer G, Stiles L, Haigh SE, Katz S, Las G et al (2008) Fission and selective fusion govern mitochondrial segregation and elimination by autophagy. EMBO J 27:433-446 
18. Johnson ML, Robinson MM, Nair KS (2013) Skeletal muscle aging and the mitochondrion. Trends Endocrinol Metab 24:247-256

19. Wang W, Fang H, Groom L, Cheng A, Zhang W, Liu J, Wang X, Li $\mathrm{K}$, Han P, Zheng $\mathrm{M}$ et al (2008) Superoxide flashes in single mitochondria. Cell 134:279-290

20. Wei-LaPierre L, Gong G, Gerstner BJ, Ducreux S, Yule DI, Pouvreau S, Wang X, Sheu SS, Cheng H, Dirksen RT et al (2013) Respective contribution of mitochondrial superoxide and $\mathrm{pH}$ to mitochondria-targeted circularly permuted yellow fluorescent protein (mt-cpYFP) flash activity. J Biol Chem 288:10567-10577

21. Zhang X, Huang Z, Hou T, Xu J, Wang Y, Shang W, Ye T, Cheng H, Gao F, Wang X (2013) Superoxide constitutes a major signal of mitochondrial superoxide flash. Life Sci 93:178-186

22. Fang H, Chen M, Ding Y, Shang W, Xu J, Zhang X, Zhang W, Li K, Xiao Y, Gao F et al (2011) Imaging superoxide flash and metabolism-coupled mitochondrial permeability transition in living animals. Cell Res 21:1295-1304

23. Wang X, Jian C, Zhang X, Huang Z, Xu J, Hou T, Shang W, Ding Y, Zhang W, Ouyang M et al (2012) Superoxide flashes: elemental events of mitochondrial ROS signaling in the heart. J Mol Cell Cardiol 52:940-948

24. Shen EZ, Song CQ, Lin Y, Zhang WH, Su PF, Liu WY, Zhang P, $\mathrm{Xu}$ J, Lin N, Zhan C et al (2014) Mitoflash frequency in early adulthood predicts lifespan in Caenorhabditis elegans. Nature 508:128-132

25. Wang X, Fang H, Huang Z, Shang W, Hou T, Cheng A, Cheng H (2013) Imaging ROS signaling in cells and animals. J Mol Med (Berl) 91:917-927

26. Hou T, Zhang X, Xu J, Jian C, Huang Z, Ye T, Hu K, Zheng M, Gao F, Wang X et al (2013) Synergistic triggering of superoxide flashes by mitochondrial $\mathrm{Ca} 2+$ uniport and basal reactive oxygen species elevation. J Biol Chem 288:4602-4612

27. Ma Q, Fang H, Shang W, Liu L, Xu Z, Ye T, Wang X, Zheng M, Chen Q, Cheng H (2011) Superoxide flashes: early mitochondrial signals for oxidative stress-induced apoptosis. J Biol Chem 286: 27573-27581

28. Li K, Zhang W, Fang H, Xie W, Liu J, Zheng M, Wang X, Wang W, Tan W, Cheng H (2012) Superoxide flashes reveal novel properties of mitochondrial reactive oxygen species excitability in cardiomyocytes. Biophys J 102:1011-1021

29. Cao Y, Zhang X, Shang W, Xu J, Wang X, Hu X, Ao Y, Cheng H (2013) Proinflammatory cytokines stimulate mitochondrial superoxide flashes in articular chondrocytes and in vitro and in situ. PLoS One 8:e66444

30. Kubota N, Terauchi Y, Kubota T, Kumagai H, Itoh S, Satoh H, Yano W, Ogata H, Tokuyama K, Takamoto I et al (2006) Pioglitazone ameliorates insulin resistance and diabetes by both adiponectin-dependent and -independent pathways. J Biol Chem 281:8748-8755

31. Schuh RA, Jackson KC, Khairallah RJ, Ward CW, Spangenburg EE (2012) Measuring mitochondrial respiration in intact single muscle fibers. Am J Physiol Regul Integr Comp Physiol 302:R712-R719

32. Davis RC, Castellani LW, Hosseini M, Ben-Zeev O, Mao HZ, Weinstein MM, Jung DY, Jun JY, Kim JK, Lusis AJ et al (2010) Early hepatic insulin resistance precedes the onset of diabetes in obese C57BLKS-db/db mice. Diabetes 59:1616-1625
33. Wei L, Salahura G, Boncompagni S, Kasischke KA, Protasi F, Sheu SS, Dirksen RT (2011) Mitochondrial superoxide flashes: metabolic biomarkers of skeletal muscle activity and disease. FASEB J 25: 3068-3078

34. Ogata T, Yamasaki Y (1985) Scanning electron-microscopic studies on the three-dimensional structure of mitochondria in the mammalian red, white and intermediate muscle fibers. Cell Tissue Res 241: 251-256

35. Kelley DE, He J, Menshikova EV, Ritov VB (2002) Dysfunction of mitochondria in human skeletal muscle in type 2 diabetes. Diabetes 51:2944-2950

36. Huang X, Sun L, Ji S, Zhao T, Zhang W, Xu J, Zhang J, Wang Y, Wang X, Franzini-Armstrong C et al (2013) Kissing and nanotunneling mediate intermitochondrial communication in the heart. Proc Natl Acad Sci U S A 110:2846-2851

37. Chen H, Vermulst M, Wang YE, Chomyn A, Prolla TA, McCaffery JM, Chan DC (2010) Mitochondrial fusion is required for mtDNA stability in skeletal muscle and tolerance of mtDNA mutations. Cell 141:280-289

38. Parone PA, Da Cruz S, Tondera D, Mattenberger Y, James DI, Maechler P, Barja F, Martinou JC (2008) Preventing mitochondrial fission impairs mitochondrial function and leads to loss of mitochondrial DNA. PLoS One 3:e3257

39. Narendra D, Tanaka A, Suen DF, Youle RJ (2008) Parkin is recruited selectively to impaired mitochondria and promotes their autophagy. J Cell Biol 183:795-803

40. Geisler S, Holmstrom KM, Skujat D, Fiesel FC, Rothfuss OC, Kahle PJ, Springer W (2010) PINK1/Parkin-mediated mitophagy is dependent on VDAC1 and p62/SQSTM1. Nat Cell Biol 12:119131

41. Kim I, Rodriguez-Enriquez S, Lemasters JJ (2007) Selective degradation of mitochondria by mitophagy. Arch Biochem Biophys 462:245-253

42. Wisloff U, Najjar SM, Ellingsen O, Haram PM, Swoap S, Al-Share Q, Fernstrom M, Rezaei K, Lee SJ, Koch LG et al (2005) Cardiovascular risk factors emerge after artificial selection for low aerobic capacity. Science 307:418-420

43. Cariou B, Charbonnel B, Staels B (2012) Thiazolidinediones and PPARgamma agonists: time for a reassessment. Trends Endocrinol Metab 23:205-215

44. Wilson-Fritch L, Nicoloro S, Chouinard M, Lazar MA, Chui PC, Leszyk J, Straubhaar J, Czech MP, Corvera S (2004) Mitochondrial remodeling in adipose tissue associated with obesity and treatment with rosiglitazone. J Clin Invest 114:1281-1289

45. Tontonoz P, Spiegelman BM (2008) Fat and beyond: the diverse biology of PPARgamma. Annu Rev Biochem 77:289-312

46. Eriksson JW (2007) Metabolic stress in insulin's target cells leads to ROS accumulation - a hypothetical common pathway causing insulin resistance. FEBS Lett 581:3734-3742

47. Wellen KE, Thompson CB (2010) Cellular metabolic stress: considering how cells respond to nutrient excess. Mol Cell 40:323-332

48. Youle RJ, van der Bliek AM (2012) Mitochondrial fission, fusion, and stress. Science 337:1062-1065

49. Liu R, Jin P, Yu L, Wang Y, Han L, Shi T, Li X (2014) Impaired mitochondrial dynamics and bioenergetics in diabetic skeletal muscle. PLoS One 9:e92810 